\title{
Cardiopulmonary resuscitation and the RECOVER guidelines at the Faculty of Veterinary Medicine, Ghent University
}

\author{
Cardiopulmonaire resuscitatie en de RECOVER-richtlijnen op de \\ Faculteit Diergeneeskunde, Universiteit Gent
}

\author{
F. Verdoodt, T. Roggeman, I. Polis
}

Small Animal Department, Faculty of Veterinary Medicine, Ghent University, Salisburylaan 133, B-9820 Merelbeke

Fien.verdoodt@ugent.be

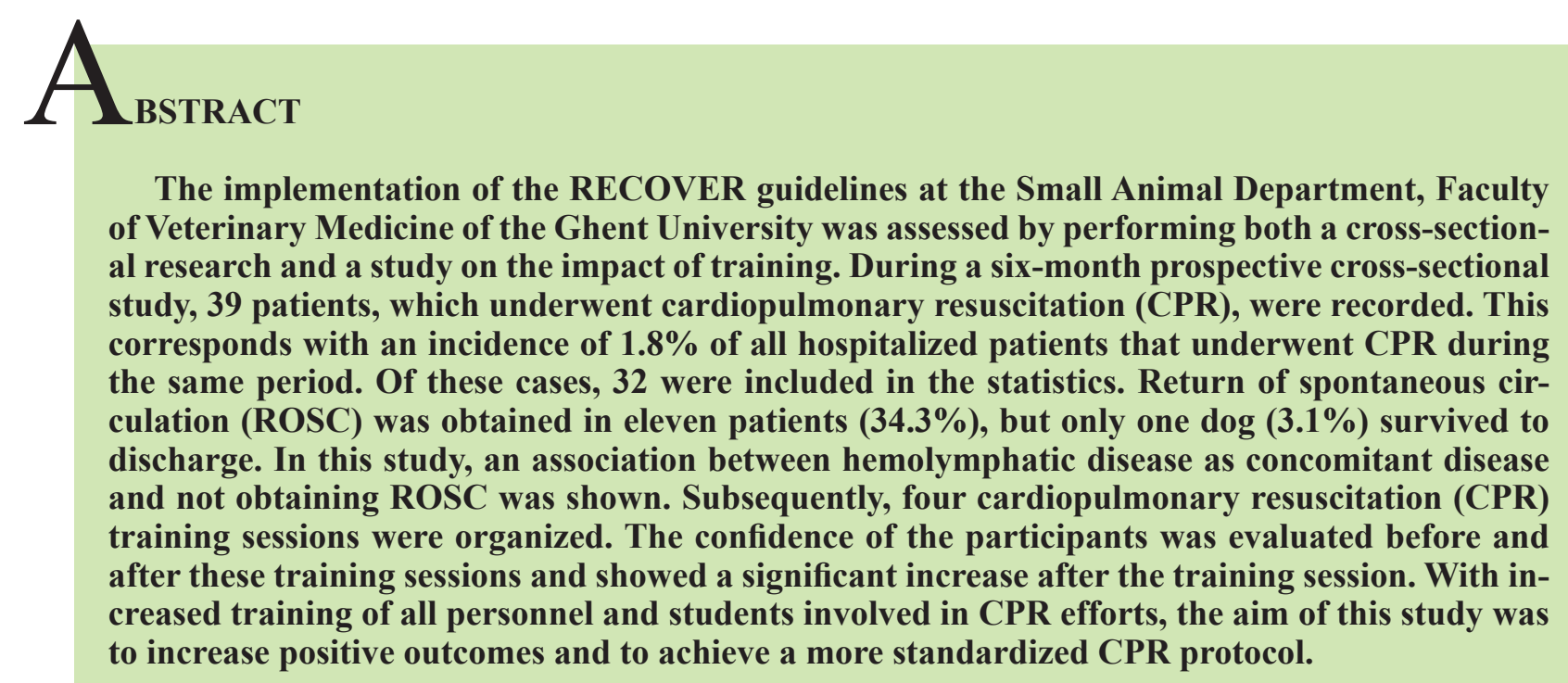

\section{SAMENVATTING}

De toepassing van de RECOVER-richtlijnen op de Vakgroep Kleine Huisdieren van de Faculteit Diergeneeskunde van de Universiteit Gent werd getoetst aan de hand van een cross-sectioneel onderzoek en het bestuderen van reanimatietrainingen. In een prospectief cross-sectioneel onderzoek werden gedurende zes maanden 39 patiënten die cardiopulmonaire resuscitatie (CPR) ondergingen, opgevolgd. Dit komt overeen met 1,8\% van de totale gehospitaliseerde populatie die in deze periode CPR ondergingen. Na het toepassen van de inclusiecriteria werden reanimatiesfiches van 32 patiënten verder geanalyseerd. Daarbij werd opnieuw spontane circulatie bekomen bij elf dieren $(34,3 \%)$, maar slechts één hond (3,1\%) overleefde tot thuiskomst na opname in de kliniek. Daarnaast werd een verband gezien tussen het voorkomen van een hemolymfatische aandoening en het niet bekomen van ROSC. Vervolgens werden vier reanimatietrainingen georganiseerd. Daaruit bleek dat het zelfvertrouwen van de deelnemers significant gestegen was na het bijwonen van de training. Het doel van de studie was om de uitkomst van reanimaties te verbeteren en een meer gestandaardiseerd CPR-protocol te ontwikkelen door de reanimatietraining van betrokken personeel en studenten te optimaliseren.

\section{INTRODUCTION}

After a cardiopulmonary arrest (CPA), less than $6 \%$ of canine and feline patients survive until discharge (Kass and Haskins, 1992; Boller et al., 2010;
Boller and Fletcher, 2012; Hofmeister et al., 2019). In human medicine, this survival rate is approximately $5-20 \%$ for in-hospital CPA (Cooper et al., 2006; Peberdy et al., 2008). This could indicate that there is room for improvement in the cardiopulmonary resus- 
citation (CPR) procedure in small animals. However, the underlying cause plays an important role in the difference between human and veterinary patients. Dogs and cats for instance often have severe irreversible causes underlying the arrest, while an arrest in humans is more often caused by a primary cardiovascular cause, which might be reversible (Hofmeister et al., 2009).

Therefore the Reassessment Campaign On Veterinary Resuscitation (RECOVER) was established: an international panel of more than eighty veterinarians who reviewed the current state-of-the-art for CPR in order to identify knowledge gaps and create uniform guidelines (Boller and Fletcher, 2012). In 2012, they published their first consensus statement. This statement is divided into five domains: Preparedness and prevention, basic life support (BLS), advanced life support (ALS), monitoring and post-resuscitation care. For each domain, the literature was reviewed to set up guidelines based on qualitative scientific evidence and identify knowledge gaps. In September 2020, an update on the 2012 guidelines was published. In this update, the same principles and guidelines as in 2012 are described, but with strong emphasis on postcardiac arrest care to address the discrepancy between patients achieving return of spontaneous circulation (ROSC) and patients surviving until discharge (Boller and Fletcher, 2020).

In this article, the implementation of the RECOVER guidelines at the Small Animal Department at the Faculty of Veterinary Medicine is described. At the start of the study (March 2019), no data were available about the incidence and performance of CPR at this facility. Therefore, the first aim of this study was to collect information by executing a prospective cross-sectional research. The CPR-sheets to obtain this information were designed in a way to also have a more standardized adherence with RECOVER guidelines during CPR (Figure 1). A second aim of this study was to set up training sessions as a means of improving the preparedness and prevention measures in the future.

\section{MATERIALS AND METHODS}

\section{Cross-sectional study}

In order to collect more information about CPR performed at the Small Animal Department, Faculty of Veterinary Medicine, Ghent University, a prospective cross-sectional study was set up. CPR-sheets were designed based on the Utstein-guidelines (Boller et al., 2016) (Figure 2). On one side of the sheet, all main information was collected during CPR. On the back, more details were added concerning the patient, underlying/concomitant disease and the process of resuscitation. The back of the sheet was also used as a baseline for debriefing.
During the study period (March 2019-August 2019), CPR sheets were available in the ICU and in the preparation area of the surgical theatres. Veterinarians, interns and students were informed about the use of the CPR sheets via email, social media and an informative meeting in spring 2019. In order to avoid missing data, the CPR sheets were collected weekly and an active enquiry about events in the past week was engaged.

The collected variables regarding the patient, CPR-process and outcome were based on recent RECOVER-oriented studies (Hogen et al., 2018; Kawase et al., 2018, Hoehne et al., 2019; Hoehne et al., 2019a) (Table 1). All patients who suffered from a CPA were qualified as a potential study subject when a CPR-attempt was made. Inclusion criteria included age, breed, underlying cause, duration of CPR and outcome. After implementation of these criteria, data from 32 out of $39 \mathrm{CPR}$-sheets were processed using SPSS 26 and Excel.

\section{Definitions}

The variability in possible underlying causes or concomitant diseases was high. Therefore, a subdivision in categories was made, based on the affected organ system. The definitions were extrapolated from a recent Japanese study (Kawase et al., 2018), as illustrated further (Table 2).

Furthermore, three main medical treatment options, as advised by RECOVER (Rozanski et al., 2012), were recorded. Firstly, the use of low-dose epinephrine 0.01 $\mathrm{mg} / \mathrm{kg}$ given intravenously (IV) (Adrenaline HCL 0.8 $\mathrm{mg} / \mathrm{ml}$, Laboratoria Sterop NV, Brussels, Belgium) was recorded. This is advised in patients with nonshockable arrest rhythms. Secondly, the use of highdose epinephrine at $0.1 \mathrm{mg} / \mathrm{kg}$ IV was recorded. This is only advised in prolonged CPR, i.e. CPR with a duration longer than ten minutes. Finally, the use of atropine (Atropine sulfate, $1 \mathrm{mg} / \mathrm{ml}$, Laboratoria Sterop NV, Brussels, Belgium) given IV at a dose of 0.04 $\mathrm{mg} / \mathrm{kg}$ was recorded. This is advised in patients with an increase in vagal tone. All CPR sheets were analyzed to assess the use of these medical treatment options, but the precise moment of administration was not considered.

Regarding the different outcome possibilities, the most important distinction was made between sustained ROSC and death. ROSC is defined as restoration of the effective circulation for at least thirty seconds. This is assessed by clinical signs, such as palpable pulses, systolic blood pressure measurements $>$ $60 \mathrm{mmHg}$ or a marked increase in $\mathrm{EtCO}_{2}$ (Boller et al., 2016). Sustained ROSC is defined as ROSC that lasts at least twenty minutes. When this is achieved, three options remain: re-arrest, euthanasia before discharge or survival until discharge. Death can occur when no ROSC is obtained or after a short period of ROSC (less than twenty minutes). Furthermore, the 


\section{CPR Algorithm}

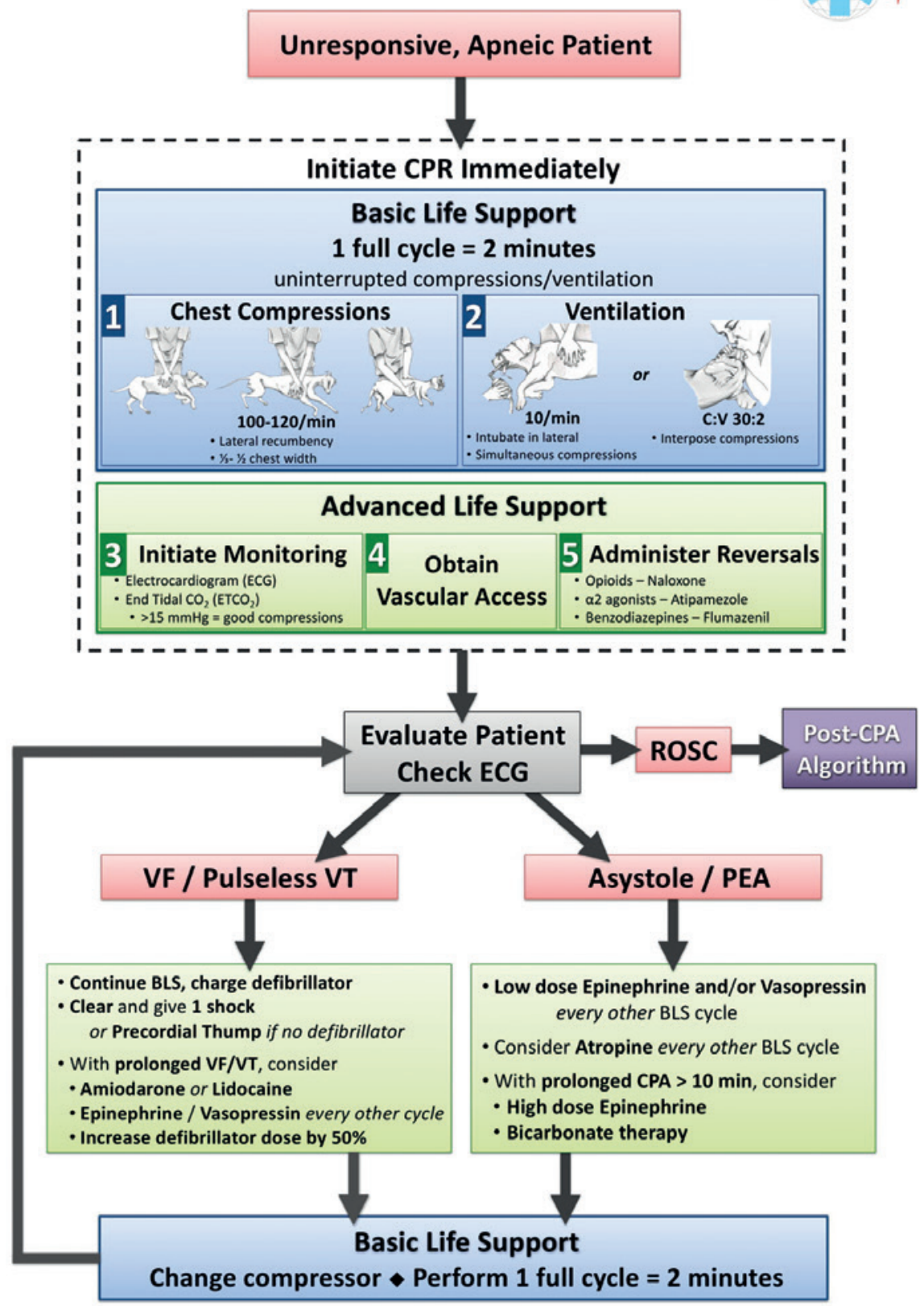

Reprinted with permission from Fletcher et al., J Vet Emerg Crit Care, 22(S1): S102-\$131, 2012

Figure 1. RECOVER guidelines explained in the CPR algorithm.

lack of achieving ROSC can be both due to the lack of response to the CPR attempt or after CPR disruption. The decision for disruption is made by the owner or the clinician. The CPR outcome (ROSC versus unresponsive to advanced life support versus owner's/ clinician's decision to stop) was not consistently completed in the CPR sheet. For this reason, cases where no ROSC was obtained within twenty minutes without specific mentioning of disruption of CPR were classified as 'lack of response', while cases where a reason to stop CPR was mentioned on the CPR sheet were classified as a disruption of CPR.

\section{Statistical analysis}

A comparison was made between dogs in which sustained ROSC was achieved and dogs that did not achieve sustained ROSC, to assess if any of the recorded variables caused a significant difference between those two groups. Furthermore, the same comparison was made between dogs with any ROSC and dogs in which no ROSC was achieved.

A Shapiro-Wilk test was run on the continuous data to assess normal distribution. Non-normally distributed variables were analyzed using a Mann-Whitney 


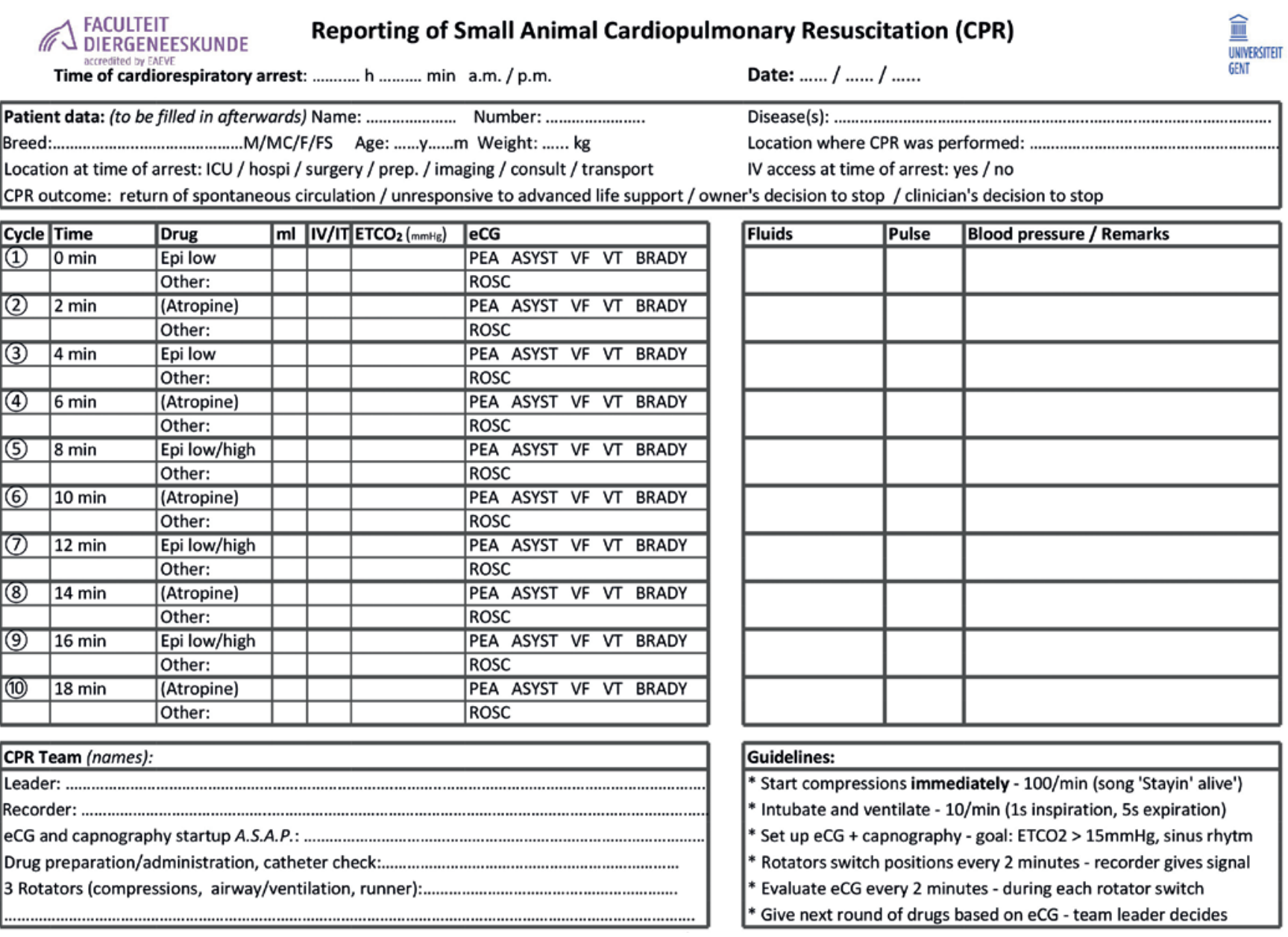

Figure 2. CPR sheet - frontside.

U-test (i.e. duration and weight), normally distributed continuous variables were analyzed using an independent T-test (i.e. age and number of helpers involved). Categorical data were analyzed using logistic regression (i.e. concomitant disease), chi ${ }^{2}$ - test (i.e. species, breed, sex, IV catheter in place, outcome) or Fisher's exact test (medication). All tests were analyzed using a 95\% -confidence interval in SPSS 26.

\section{Training}

As indicated by the RECOVER guidelines, CPR training should take place at least every six months (Woollard et al., 2006). Currently, this condition is not met at the Small Animal Department, Faculty of Veterinary Medicine, Ghent University. Therefore, four training sessions were organized for last-year veterinary students and veterinary technicians, but not for the veterinarians currently working at the Small Animal Department. Every session was attended by ten participants and followed the same routine.

The training was compiled in accordance to the RECOVER guidelines by providing first a theoretical part followed by a realistic simulation (Fletcher et al., 2012). During the first part, the CPR algorithm was thoroughly explained, and the key-aspects of every step were emphasized. During the practical part, the participants were divided into two groups. One group performed a simulated resuscitation attempt, while the other group critically observed the training. Afterwards, both groups switched positions. Therefore, two resuscitation scenarios were provided. The session ended with an extensive debriefing moment for all participants.

For the simulation, the Advanced airway Jerry K-9 CPR Mannikin (Rescue critters! ${ }^{\circledR}$, United States) was used. Furthermore, equipment like emergency drugs, endotracheal tubes and syringes were provided. Monitoring was simulated by a diagrammatic electrocardiogram (ECG) and capnogram on paper following a specific scenario. Those diagrams were only visible when all monitoring equipment was connected. More precisely, the ECG only showed an interpretable signal when pausing the chest compressions, to simulate the real-life situation.

To evaluate the training, all participants scored their confidence before and after training. This happened by sending a brief questionnaire via email. Each participant scored him/herself regarding confidence in theoretical knowledge and practical skills with a score 
Table 1. Overview of variables recorded using CPR sheets.

\begin{tabular}{ll}
\hline Category & Recorded variables \\
\hline Patient & Species-breed-age-weight-sex \\
CPR process & Duration-number of helpers involved-iv catheter in place-medication-concomitant disease \\
Outcome & Sustained ROSC-death (cf. Figure 3) \\
\hline
\end{tabular}

Table 2. Concomitant disease categories.

\begin{tabular}{|c|c|c|c|}
\hline Category & Description & Examples & $\begin{array}{l}\text { Number } \\
\text { of patients }\end{array}$ \\
\hline Circulatory & $\begin{array}{l}\text { Heart disease including congestive } \\
\text { heart failure }\end{array}$ & $\begin{array}{l}\text { Congestive heart failure, pericardial } \\
\text { tamponade }\end{array}$ & 2 \\
\hline Respiratory & $\begin{array}{l}\text { Dyspnea or abnormal findings on chest } \\
\text { radiography with abnormal blood gas } \\
\text { oxygenation or ventilatory function }\end{array}$ & Pleural effusion*, pneumothorax & 7 \\
\hline Hemolymphatic & $\begin{array}{l}\text { Disseminated intravascular coagulation (DIC), } \\
\text { coagulopathy, anemia, leukemia, or tumors } \\
\text { such as splenic tumors that involve the blood } \\
\text { or lymphatic system }\end{array}$ & IMHA, hemangiosarcoma & 6 \\
\hline Neurological & $\begin{array}{l}\text { Abnormalities in the central or peripheral } \\
\text { nervous system }\end{array}$ & $\begin{array}{l}\text { Central vestibular disease*, } \\
\text { polyneuropathy, brain surgery }\end{array}$ & 4 \\
\hline Digestive & $\begin{array}{l}\text { Diseases of the liver and digestive tract } \\
\text { such as ileus, vomiting, or intestinal resection }\end{array}$ & $\begin{array}{l}\text { Duodenitis-cholangiocystitis, } \\
\text { foreign body in gastro-intestinal tract }\end{array}$ & 2 \\
\hline $\begin{array}{l}\text { Multiple organ } \\
\text { failure }\end{array}$ & $\begin{array}{l}\text { The presence of abnormalities in two or } \\
\text { more organ systems with systemic } \\
\text { inflammation or progressive DIC }\end{array}$ & $\begin{array}{l}\text { Hit by car, leptospirosis, multiple } 10 \\
\text { chronic diseases (heart, kidney, } \\
\text { pancreatitis) }\end{array}$ & \\
\hline Other & $\begin{array}{l}\text { Causes of CPR that are not classified into } \\
\text { any of the preceding categories }\end{array}$ & Post-operative nephrectomy & 1 \\
\hline
\end{tabular}

Disease present in patients that achieved sustained ROSC are indicated with *

between 0 and 10 . These scores were compared before and after training with a paired T-test.

\section{RESULTS}

\section{Cross-sectional study}

\section{Patients}

During the study period, 2209 patients were hospitalized and CPR was performed in 39 cases. This indicates that CPR had an incidence of $1.8 \%$ at the Small Animal Department during the period MarchAugust 2019 (Table 3). Of these 39 cases, 32 cases met the inclusion criteria and were used for further data processing.

The age of the CPR patients was normally distributed with a mean of $6.6 \pm 4.1$ years. Age was not significantly different in patients with sustained ROSC compared to patients without sustained ROSC $(\mathrm{P}=$
0.950), nor in patients with ROSC compared to patients with no ROSC $(\mathrm{P}=0.397)$.

In the studied population, there were 18 male and 14 female patients. No significant difference was found between patients with sustained ROSC and patients without sustained ROSC $(\mathrm{P}=0.886)$, nor between patients with any ROSC and those with no $\operatorname{ROSC}(\mathrm{P}=$ 0.264 ).

The median weight of the resuscitated population was $10.3 \mathrm{~kg}(0.9 \mathrm{~kg}-52.5 \mathrm{~kg})$. No significant difference was found between patients with sustained ROSC and patients without sustained ROSC $(\mathrm{P}=$ 0.419 ), nor between patients with any ROSC and patients with no $\operatorname{ROSC}(\mathrm{P}=0.785)$.

\section{Resuscitation}

During the resuscitation attempt, $5.5 \pm 1.7$ individuals participated and an attempt lasted for $12.5 \pm$ 7.9 minutes. It was not possible to distinguish veterinarians, veterinary students and technicians as partici- 
Table 3. Patient population Small Animal Department of Ghent University March-August 2019.

\begin{tabular}{lcc}
\hline \multicolumn{2}{c}{ Small Animal Department - Ghent University } \\
\hline Population & Absolute number & Percentage \\
\hline Total hospitalized & $\mathbf{2 2 0 9}$ & $\mathbf{1 0 0 \%}$ \\
Feline & 489 & $22 \%$ \\
Canine & 1719 & $78 \%$ \\
Reanimations & $\mathbf{3 9}$ & $\mathbf{2 \%}$ \\
Feline & 9 & $23 \%$ \\
Canine & 25 & $64 \%$ \\
Species not recorded & 5 & $13 \%$ \\
\hline
\end{tabular}

pants with the available information. Neither of these variables showed a significant difference between patients with sustained ROSC and patients without sustained $\operatorname{ROSC}(\mathrm{P}=0.386$ for number of participants, $\mathrm{P}=0.855$ for duration) nor between patients with any ROSC and no ROSC $(\mathrm{P}=0.587$ for number of participants, $\mathrm{P}=0.223$ for duration). In $96.8 \%$ (31 patients) of the cases, the patient received low-dose epinephrine, $68.8 \%$ (22 patients) of the cases received highdose epinephrine and 37.5\% (12 patients) received atropine. In five of the cases that received high-dose epinephrine, the duration of CPR was shorter than ten minutes. For the other 17 cases, the precise moment of administration was not recorded. A Fisher's Exact test showed that patients with sustained ROSC $(\mathrm{N}=3)$ received significantly more atropine than patients without sustained $\operatorname{ROSC}(\mathrm{N}=31)(\mathrm{P}=0.044)$.

In $96.8 \%$ of the patients, an IV catheter was in place before the CPA occurred.

Finally, logistic regression showed a significant effect for concomitant diseases of the hemolymphatic category. An association was found between patients with a hemolymphatic disease and not obtaining any ROSC (B-value $=-22,302$ ). An anesthesia-related event was only recorded for one patient in the category digestive. In patients with sustained ROSC, the underlying conditions were dyspnea, pleural effusion and central vestibular disorder (Table 2).

\section{Outcome}

Sustained ROSC was obtained in three of the 32 recorded resuscitations, together with eight patients achieving any ROSC in less than 20 minutes. This means that in total, $34.3 \%$ (eleven patients) of the studied population achieved any type of ROSC. Only one patient or $3.1 \%$ of the studied population survived until discharge.

CPR was discontinued in 18 patients. This corresponds to $56.3 \%$ of the studied population. In seven cases, this decision was made by the clinician and in ten cases by the owner. In one case, it was not clear who made the decision (Figure 3 ).

\section{Training}

The pre- and post-training questionnaires were completed by 37 participants. The majority of the participants, i. e. $81.1 \%$ (30 participants), had already experienced a real resuscitation attempt before the training started.

Thirty four out of 37 participants completed both questionnaires. Their answers were therefore included in the statistical analysis. The mean scores before training were $5.1 \pm 0.3$ for theoretical knowledge and $4.8 \pm 0.3$ for practical skills. The mean scores after training were respectively $7.6 \pm 0.2$ and $7.5 \pm 0.2$. This revealed a significant improvement in confidence in performing a CPR when comparing the post-training scores with the pre-training scores $(\mathrm{P}<0.001)$.

\section{DISCUSSION}

The results obtained for the training session met the expectations and were non-ambiguous.

With regard to the cross-sectional study, $1.8 \%$ of the patients admitted to the Small Animal Department underwent CPR. There were three main reasons for possible bias on this reported incidence. Firstly, the veterinarians and students were not completely familiar with the use of the CPR sheets at the beginning of the study. It was the first time that these sheets were used at the Small Animal Department, so possibly some students or veterinarians forgot to complete a CPR sheet for each case. Secondly, a CPR attempt is inherent to be unexpected and stressful, which can interfere with the recording of the required data. Indeed, it was emphasized that a good execution of CPR is more important than the use of CPR sheets. To minimize these two underestimating biases, CPR sheets were collected weekly and an active enquiry for possible non-recorded events was performed. Finally, it needs to be considered that the study took place in a referral, university hospital environment. The risk of anesthetic related CPA was therefore reduced, because routine preanesthetic clinical examination and accurate monitoring during the anesthesia were per- 
formed. Both reduce the risk of CPA significantly (Matthew et al, 2017).

In this study, ROSC was obtained in $34.3 \%$ of the studied population. This is in accordance with rates found in the literature: $28-60 \%$ for canine CPR and $42-57 \%$ for feline CPR (Kass and Haskins, 1992; Hofmeister et al., 2009; McIntyre et al., 2014; Hoehne et al., 2019a). Furthermore, the survival-until-discharge rate was $3.1 \%$; this is in agreement with less than $6 \%$ as reported in multiple international studies (Kass and Haskins, 1992; Waldrop et al., 2004; Hofmeister et al., 2009; Mcintyre et al., 2014).

High-dose epinephrine was administere in $68 \%$ of the patient population. Because this is associated with an increased rate of ROSC without an increase in survival rate until discharge (Rozanski et al., 2012), RECOVER only recommends its use in prolonged CPR (Fletcher et al., 2012). For this reason, the events where high-dose epinephrine was used, were evaluated in more detail. In total, 22 patients received a high dose during CPR. In five of these cases, the duration of CPR was shorter than ten minutes. Hence, its use was not recommended according to the RECOVER guidelines. For the other 17 cases, the precise moment of administration was not recorded, so it was not possible to determine whether or not a high dose of epinephrine was administered too early. Nonetheless, it seems that the appropriate use of high-dose epinephrine is an important point of improvement.

In this study, a correlation between atropine and sustained ROSC was found. However, it is of great importance to correctly frame this result. In the study population, all three patients, in which sustained ROSC was achieved, had received atropine during CPR. However, atropine is recommended when there is an increase in vagal tone (Rozanski et al., 2012). The underlying conditions in the patients that achieved sustained ROSC were dyspnea, pleural effusion and central vestibular disorder. These conditions not only increase the vagal tone, but are more likely to be reversible and respond well to atropine, which causes a higher chance of achieving sustained ROSC. Hence, it is suspected that not atropine itself, but the underlying conditions and the management of these cases attributed to the correlation with sustained ROSC.

Other underlying conditions that correlated with the outcome in the present study were hemolymphatic disorders. They showed a negative predictive value for achieving ROSC. The most common condition in this category (four of six patients) was immune-mediated hemolytic anemia (IMHA). During the study period, a total of 28 patients with IMHA were presented at the Small Animal Department, indicating that $14.3 \%$ of them suffered from CPA. This is a much

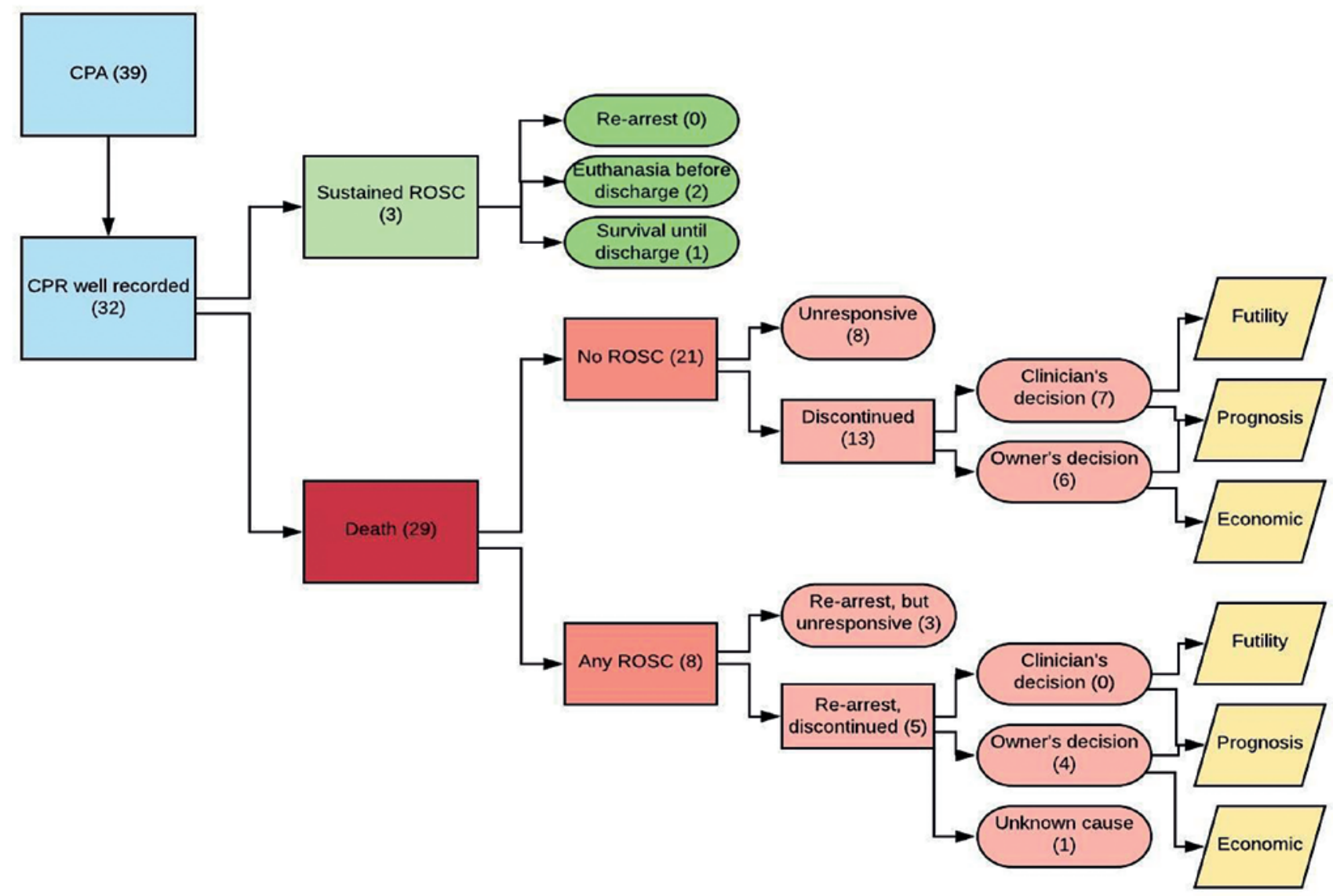

Figure 3. Visualization of CPR outcome. The number of patients in each category are put between brackets. 
higher incidence than the CPA incidence of $1.8 \%$ for the general population in the same period. This is not surprising since mortality rates in IMHA of up to 50$70 \%$ have been described in the literature (Swann and Skelly, 2013).

Finally, the true potential of sustained ROSC in patients undergoing $\mathrm{CPR}$ requires attention. In the present study however, discontinuation of the CPR attempt was recorded in $56.3 \%$ of the cases. This decision was either made by the clinician or the owner but no motivation was specified. The most important reasons to opt for discontinuation are a poor prognosis and economic reasons (Boller et al., 2016). The true potential of sustained ROSC in patients undergoing CPR can only be obtained if these restraints do not interfere with the outcome, which is not feasible in real-life situations.

\section{REFERENCES}

Boller, M., Fletcher, D.J. (2020). Update on cardiopulmonary resuscitation in small animals. Veterinary Clinics of North America: Small Animal Practice 50, 1183-1202.

Boller, M., Fletcher, D.J. (2012). RECOVER evidence and knowledge gap analysis on veterinary CPR. Journal of Veterinary Emergency and Critical Care 22, 4-12.

Boller, M., Fletcher, D.J., Brainard, B.M., Haskins, S., Hopper, K., Nadkarni, V.M., Morley, P.T., Mcmichael, M., Nishimura, R., Robben, J.H., Rozanski, E., Rudloff, E., Rush, J., Shih, A., Smarick, S., Tello, L.H. (2016). Utstein-style guidelines on uniform reporting of in-hospital cardiopulmonary resuscitation in dogs and cats. A RECOVER statement. Journal of Veterinary Emergency and Critical Care 26, 11-34.

Boller, M., Kellett-Gregory, L., Shofer, F.S., Rishniw, M. (2010). The clinical practice of CPCR in small animals: An internet-based survey. Journal of Veterinary Emergency and Critical Care 20, 558-570.

Cooper, S., Janghorbani, M., Cooper, G. (2006). A decade of in-hospital resuscitation: Outcomes and prediction of survival? Resuscitation 68, 231-237.

Fletcher, D.J., Boller, M., Brainard, B.M., Haskins, S.C., Hopper, K., Mcmichael, M.A., Rozanski, E.A., Rush, J.E., Smarick, S.D. (2012). RECOVER evidence and knowledge gap analysis on veterinary CPR. Journal of Veterinary Emergency and Critical Care 22, 102-131.

Hoehne, Sabrina N, Epstein, S.E., Hopper, K. (2019). Prospective evaluation of cardiopulmonary resuscitation performed in dogs and cats according to the RECOVER guidelines. Frontiers in Veterinary Science 6, 1-10.

Hoehne, Sabrina N., Hopper, K., Epstein, S.E. (2019). Prospective evaluation of cardiopulmonary resuscitation performed in dogs and cats according to the RECOVER guidelines. Frontiers in Veterinary Science 10, 439.
Hofmeister, E.H., Brainard, B.M., Egger, C.M., Kang, S. (2009). Prognostic indicators for dogs and cats with cardiopulmonary arrest treated by cardiopulmonary cerebral resuscitation at a university teaching hospital. Journal of the American Veterinary Medical Association 235, 50-57.

Hogen, T., Cole, S.G., Drobatz, K.J. (2018). Evaluation of end-tidal carbon dioxide as a predictor of return of spontaneous circulation in dogs and cats undergoing cardiopulmonary resuscitation. Journal of Veterinary Emergency and Critical Care 28, 398-407.

Kass, P.H., Haskins, S.C. (1992). Survival following cardiopulmonary resuscitation in dogs and cats. Journal of Veterinary Emergency and Critical Care 2, 57-65.

Kawase, K., Ujiie, H., Takaki, M., Yamashita, K. (2018). Clinical outcome of canine cardiopulmonary resuscitation following the RECOVER clinical guidelines at a Japanese nighttime animal hospital. Journal of Veterinary Medical Science 80, 518-525.

Mcintyre, R.L., Hopper, K., Epstein, S.E. (2014). Assessment of cardiopulmonary resuscitation in 121 dogs and 30 cats at a university teaching hospital (2009-2012). Journal of Veterinary Emergency and Critical Care 24, 693-704.

Peberdy, M.A., Ornato, J.P., Larkin, G.L., Braithwaite, R.S., Kashner, T.M., Carey, S.M., Meaney, P.A., Cen, L., Nadkarni, V.M., Praestgaard, A.H., Berg, R.A. (2008). Survival from in-hospital cardiac arrest during nights and weekends. Journal of the American Medical Association 299, 785-792.

Rozanski, E.A., Rush, J.E., Buckley, G.J., Fletcher, D.J., Boller, M., Chow, R.S., Dickinson, A.E., Lagutchik, M.S., Mohammad-Zadeh, L.F., O'Marra, S.K., Odunayo, A., Powell, L.L., Rogers, C.L., Sakakeeny, C.E., Simpson, S.A., Sullivan, L.A., Walker, T.G. (2012). RECOVER evidence and knowledge gap analysis on veterinary CPR. Journal of Veterinary Emergency and Critical Care 22, 44-64.

Swann, J.W., Skelly, B.J. (2013). Systematic review of evidence relating to the treatment of immune-mediated hemolytic anemia in dogs. Journal of Veterinary Internal Medicine 27, 1-9.

Waldrop, J.E., Rozanski, E.A., Swanke, E.D., O’Toole, T.E., Rush, J.E. (2004). Causes of cardiopulmonary arrest, resuscitation management, and functional outcome in dogs and cats surviving cardiopulmonary arrest. Journal of Veterinary Emergency and Critical Care 14, 22-29.

Woollard, M., Whitfield, R., Newcombe, R.G., Colquhoun, M., Vetter, N., Chamberlain, D. (2006). Optimal refresher training intervals for AED and CPR skills: A randomised controlled trial. Resuscitation 71, 237-247.

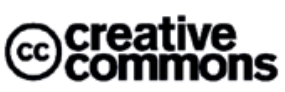

C) 2021 by the authors. Licensee Vlaams Diergeneeskundig Tijdschrift, Ghent University, Belgium. This article is an open access article distributed under the terms and conditions of the Creative Commons Attribution (CC BY) license (http://creativecommons.org/licenses/by/4.0/). 